\title{
Disruption of a Maize 9-Lipoxygenase Results in Increased Resistance to Fungal Pathogens and Reduced Levels of Contamination with Mycotoxin Fumonisin
}

\author{
Xiquan Gao, ${ }^{1}$ Won-Bo Shim, ${ }^{1}$ Cornelia Göbel, ${ }^{2}$ Susan Kunze, ${ }^{2}$ Ivo Feussner, ${ }^{2}$ Robert Meeley, ${ }^{3}$ \\ Peter Balint-Kurti, ${ }^{4}$ and Michael Kolomiets ${ }^{1}$ \\ 'Department of Plant Pathology and Microbiology, Texas A\&M University, 2132 TAMU, College Station, TX 77843-2132, \\ U.S.A.; ${ }^{2}$ Department of Plant Biochemistry, Georg-August-University, Göttingen, Justus-von-Liebig-Weg 11, D-37077 \\ Göttingen, Germany; ${ }^{3}$ Pioneer Hi-Bred Inc., 7250 NW 62nd Ave., Johnston, IA, 50131-0552, U.S.A.; ${ }^{4}$ United States \\ Department of Agriculture-Agricultural Research Service, North Carolina State University, Department of Plant Pathology, \\ Raleigh 27608-7616, U.S.A.
}

Submitted 23 February 2007. Accepted 12 April 2007.

Plant oxylipins, produced via the lipoxygenase (LOX) pathway, function as signals in defense and development. In fungi, oxylipins are potent regulators of mycotoxin biosynthesis and sporogenesis. Previous studies showed that plant 9-LOX-derived fatty acid hydroperoxides induce conidiation and mycotoxin production. Here, we tested the hypothesis that oxylipins produced by the maize 9-LOX pathway are required by pathogens to produce spores and mycotoxins and to successfully colonize the host. Maize mutants were generated in which the function of a 9-LOX gene, $\mathrm{ZmLOX3}$, was abolished by an insertion of a Mutator transposon in its coding sequence, which resulted in reduced levels of several 9-LOX-derived hydroperoxides. Supporting our hypothesis, conidiation and production of the mycotoxin fumonisin B1 by Fusarium verticillioides were drastically reduced in kernels of the lox3 mutants compared with near-isogenic wild types. Similarly, conidia production and disease severity of anthracnose leaf blight caused by Colletotrichum graminicola were significantly reduced in the lox 3 mutants. Moreover, lox3 mutants displayed increased resistance to southern leaf blight caused by Cochliobolus heterostrophus and stalk rots caused by both $F$. verticillioides and $C$. graminicola. These data strongly suggest that oxylipin metabolism mediated by a specific plant 9-LOX isoform is required for fungal pathogenesis, including disease development and production of spores and mycotoxins.

Additional keywords: lipid peroxidation.

Infection of seed with ascomycete fungi, including the genera Fusarium and Aspergillus, is a major limiting factor in maize seed production worldwide. These fungi not only macerate the seed, causing diseases known variously as ear molds or ear rots, but, more importantly, they also contaminate seed with genetoxic, teratogenic, and carcinogenic mycotoxins, the most potent of which are fumonisins and aflatoxins. Most of

Corresponding author: M. Kolomiets; E-mail: kolomiets@tamu.edu

* The $\boldsymbol{e}$-Xtra logo stands for "electronic extra" and indicates that Figure 3 appears in color online. the known hosts for mycotoxigenic fungi are oil-rich crops such as corn, peanut, cotton, and various tree nuts (Diener et al. 1987), pointing to an important role that plant lipids may have in the host-pathogen interactions.

Lipid peroxidation is an important feature of plant development and defense responses to a wide range of environmental stresses. Oxylipins are a large class of diverse oxygenated polyenoic fatty acids, the majority of which are derivatives of at least six multienzyme pathways collectively called the lipoxygenase (LOX) pathway (Feussner and Wasternack 2002). Accumulating data have shown that oxylipins produced by mammals, yeast, and fungal pathogens are important signaling molecules that regulate development of these organisms and, in pathogenic fungi, are involved in signal communication with host cells (Herman 1998; Kock et al. 2003; Noverr et al. 2003). Mammalian oxylipins, namely eicosanoids, have been shown to regulate apoptotic cell death, the cardiovascular system, and renal function and to mediate intercellular communication during resistance responses to pathogenic agents (Herman 1998; Kock et al. 2003; Noverr et al. 2003). In plants, LOXs catalyze the incorporation of molecular oxygen into free fatty acids, primarily linoleic (C18:2) and linolenic (C18:3) acids, either at position 9 or 13 of their carbon chains, and, therefore, are referred to as 9-LOXs or 13-LOXs. The resulting two distinct fatty acid hydroperoxides then enter separate biosynthetic pathways that result in the accumulation of oxylipins, some of which have diverse physiological functions as signals of intraand intercellular communication (Howe and Schilmiller 2002). The most understood functional aspects of oxylipin pathways came mainly from the studies of jasmonic acid (JA), its precursor 12-oxo-phytodienoic acid (12-OPDA), and their derivatives, collectively called jasmonates. These molecules as well as the volatile C-6 aldehyde, 3(Z)-hexenal, derived from the action of 13-LOXs on linolenic acid, serve key signaling roles in the transduction pathways that regulate expression of certain defense-related and developmental genes (Bate and Rothstein 1998; Birkett et al. 2000; Turner et al. 2002). Despite the growing awareness of oxylipin significance, the defense-related functions of the plethora of metabolites produced by the 9LOXs are poorly understood.

Largely circumstantial evidence suggests that 9-LOX pathways play an important role in defense response to pathogen 
attack (Göbel et al. 2001, 2002, 2003; Hamberg et al. 2003; Kolomiets et al. 2000; Weber et al. 1999). 9-LOX activity and its hydroperoxide metabolites were found to be sufficient to initiate programmed cell death (PCD) and hypersensitive response (HR) induced by the bacterial pathogen Ralstonia solanacearum in tobacco (Cacas et al. 2005). 9-Hydroxy octadecadienoic acid (9-HODE) and colneleic acid were significantly stimulated by Phytophthora infestans (Göbel et al. 2001), and expression of a 9-LOX gene precedes appearance of visible HR lesions (Kolomiets et al. 2000), suggesting that 9-LOXs function in defense response by synthesizing antifungal compounds or signal molecules against pathogen attack. The most convincing evidence for biological significance of 9-LOXs in plant resistance mechanisms was obtained by antisense suppression of a tobacco 9-LOX gene that resulted in the loss of HR-mediated resistance to $P$. parasitica (Rance et al. 1998), the effect most likely due to reduced levels of the 9-LOXderived colneleic and colnelenic acids (Fammartino et al. 2007). Taken together, these data provide evidence for the role of specific 9-LOXs and their derivatives as resistance factors in some plant-microbe interactions. However, convincing evidence for a potential role for 9-LOXs in facilitating pathogenic development has not been reported before this study.

In fungi, studies on the oxylipin roles are in their infancy; however, available data point to an important role that these molecules have in regulating several developmental pathways. Oxylipins produced by several fungal genera, so called psifactors (the collective term for a series of oleic, linoleic, and linolenic acid-derived oxylipins), are potent regulators of sporogenesis and are required signals for biosynthesis of mycotoxins (Brodhagen and Keller 2006; Brodowsky and Oliw 1993; Hamberg et al. 1994; Su et al. 1998). The structural and biosynthetic similarities of psi factors to plant defense oxylipins, particularly the 9-LOX products such as (9S,10E,12Z)9-hydroxy-10,12-octadecadienoic acid (9S-HODE) as well as the 13 -LOX products such as $13 S$-hydroxy-9Z,11E-octadecadienoic acid (13S-HODE), indicated that seed oxylipins may have a sporogenic effect on Aspergillus spp. (Calvo et al. 1999). This hypothesis was supported by studies showing that purified linoleic acid and hydroperoxy linoleic acids derived from peanut seed exhibit sporogenic activities toward several Aspergillus spp. (Calvo et al. 1999). Moreover, 9S-HPODE stimulated mycotoxin formation, suggesting that 9-LOX derivatives play a pivotal role in host susceptibility to mycotoxin contamination (Burow et al. 1997). In agreement with this idea, expression of a maize 9-LOX gene $Z m L O X 3$ (formerly cssap92) was induced by Fusarium verticillioides and Aspergillus flavus in lines accumulating high levels of mycotoxins (Wilson et al. 2001), suggesting that mycotoxin biosynthesis may be positively regulated by the 9-LOX products. Collectively, these data prompted the hypothesis that the 9LOX pathways are utilized by mycotoxigenic fungi to induce biosynthesis of mycotoxins and, hence, that some 9-LOX genes are susceptibility factors in maize plants (Sagaram et al. 2006; Tsitsigiannis and Keller 2006). To test this hypothesis directly, we used a transposon-tagging approach and generated maize mutants in which the Mutator $(M u)$ transposable elements were inserted in the coding sequence of the $\mathrm{ZmLOX} 3$ gene. Here, we report that inactivation of $Z m L O X 3$ resulted not only in reduced levels of fumonisin production and decreased conidiation of $F$. verticillioides but also in decreased disease severity caused by distantly related fungal pathogens Colletotrichum graminicola and Cochliobolus heterostrophus. These results strongly support the hypothesis that certain fungi may

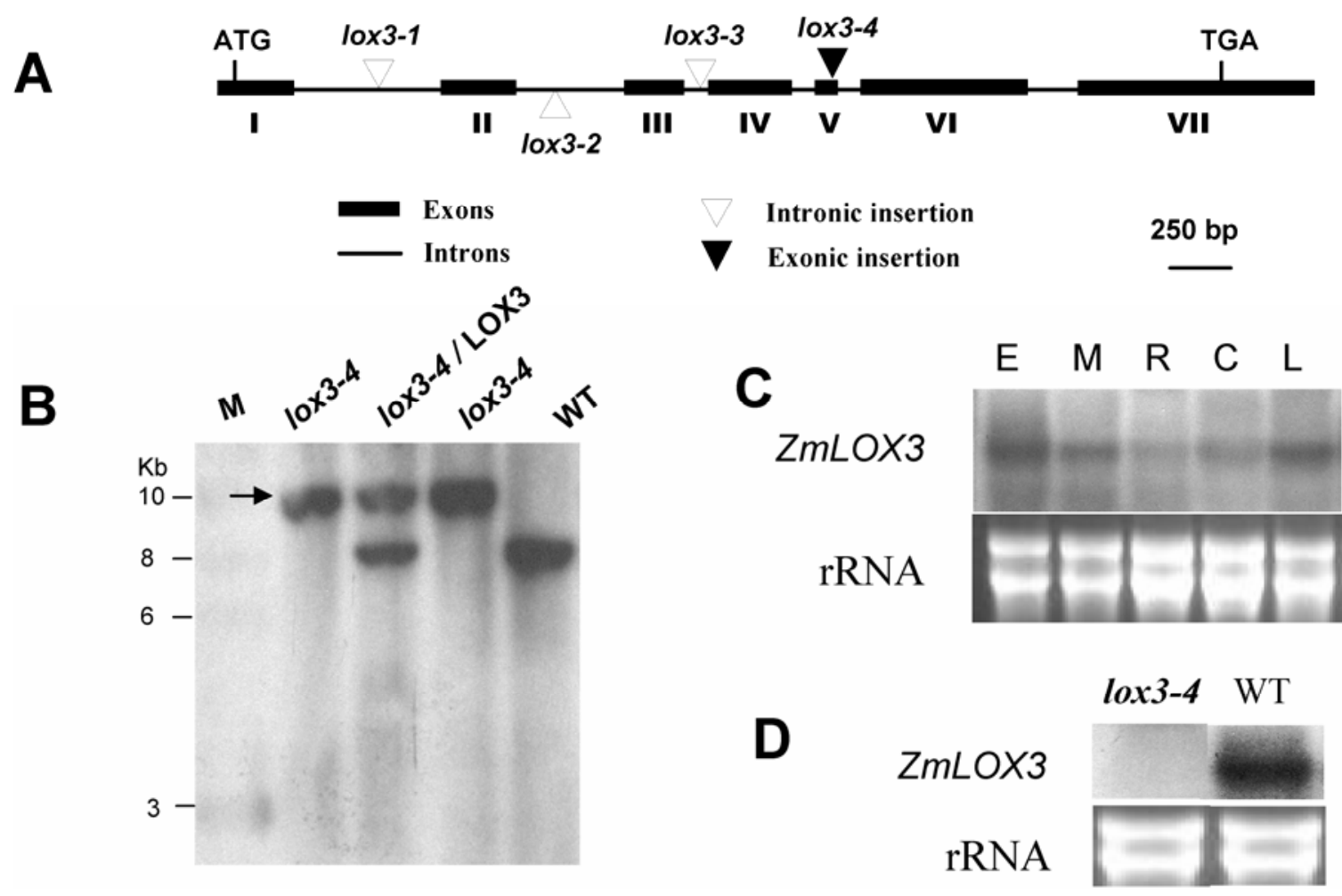

Fig. 1. Allele lox3-4 is a strong loss-of-function allele of the $Z m L O X 3$ gene. A, Schematic representation of the genomic structure of the $Z m L O X 3$ gene showing the Mutator element insertion sites. B, Southern blot analysis of ZmLOX3 genomic DNA. Genomic DNA (20 $\mu$ g) was digested with BamH1 and hybridized with the ZmLOX3 gene-specific probe. The arrow indicates the mutant band. M, molecular weight marker; lox3-4, homozygous mutant; lox34/ZmLOX3, heterozygote; WT, wild-type near-isogenic sibling. C, Northern blot analysis of organ-specific expression of ZmLOX3 in 6-day-old germinating maize seedlings. E, embryo; M, mesocotyl; R, root; C, coleoptile; L, leaf. D, Northern blot analysis of ZmLOX3 transcript in embryos of lox3-4 mutant and WT 4 days after imbibition. No hybridization signal was detected in lox3-4 mutants, indicating that lox3-4 is a strong loss-of-function allele of ZmLOX3. 
require host plant 9-LOX-derived oxylipins to upregulate their developmental processes such as conidiation and mycotoxin production.

\section{RESULTS}

The lox 3-4 mutant allele is a strong loss-of-function allele of $\mathrm{ZmLOX3}$.

The lox3 mutants were isolated by using a reverse genetics resource available at Pioneer Hi-Bred International, which is essentially a library of transposon-mutagenized seed (Meeley and Briggs 1995). To identify insertions in the ZmLOX3 gene, DNA prepared from this large population (approximately 42,000 mutagenized individuals) was screened by polymerase chain reaction (PCR) using a $M u$-specific primer in combination with several $\mathrm{ZmLOX} 3$-specific primers. Four independent alleles were identified. Sequencing of PCR fragments flanking the insertion sites revealed that $\operatorname{lox} 3-1$, lox3-2, and $\operatorname{lox} 3-3$ alleles had $M u$ insertions in introns 1, 2, and 3, respectively, whereas lox3-4 allele harbors a $M u$ element in exon V (Fig. 1A). Northern blot analysis of lox3-1, lox3-2, and lox3-3 showed wild-type levels of transcript accumulation (R. Wilson, personal communication), suggesting that these alleles are not null mutations. Therefore, no further research involving these three alleles was carried out and genetic advancing and mo- lecular characterization were performed on lox3-4 allele only. Original mutant alleles are likely to contain a number of cosegregating $M u$ elements that can confound subsequent functional analyses. To remove these unrelated mutations, we backcrossed the original mutant allele to the inbred line B73 four times $\left(\mathrm{BC}_{4}\right)$ and generated near-isogenic individuals that are either mutant or wild type at the $Z m L O X 3$ locus at the $\mathrm{BC}_{4} \mathrm{~F}_{2}$ genetic stage. This genetic stage is suitable for assessing the effect of the LOX gene knockouts on the host interactions with pathogens. To compensate for the lack of additional independent null alleles of $Z m L O X 3$, all the functional studies of this mutant were carried out with at least two mutant (4-1 and 4-2) or wild-type (5-1, 5-2, or 5-3) families that were backcrossed independently starting from the original segregating mutant population.

At the final stage of genetic advancing, $\mathrm{BC}_{4} \mathrm{~F}_{2}$ segregating mutant populations were genotyped first by PCR using $\mathrm{ZmLOX3}$-specific and $\mathrm{Mu}$-specific primers (data not shown), and the genotypes eventually were confirmed by Southern blot analysis (Fig. 1B). Homozygote mutant individuals displayed a single band that hybridized to the $Z m L O X 3$ gene-specific probe (Fig. 1B) and was approximately 2 kilobases larger in size compared with the wild-type allele band, a difference expected from a $M u$ insertion in the gene. As expected, heterozygote individuals displayed both the wild-type and mutant

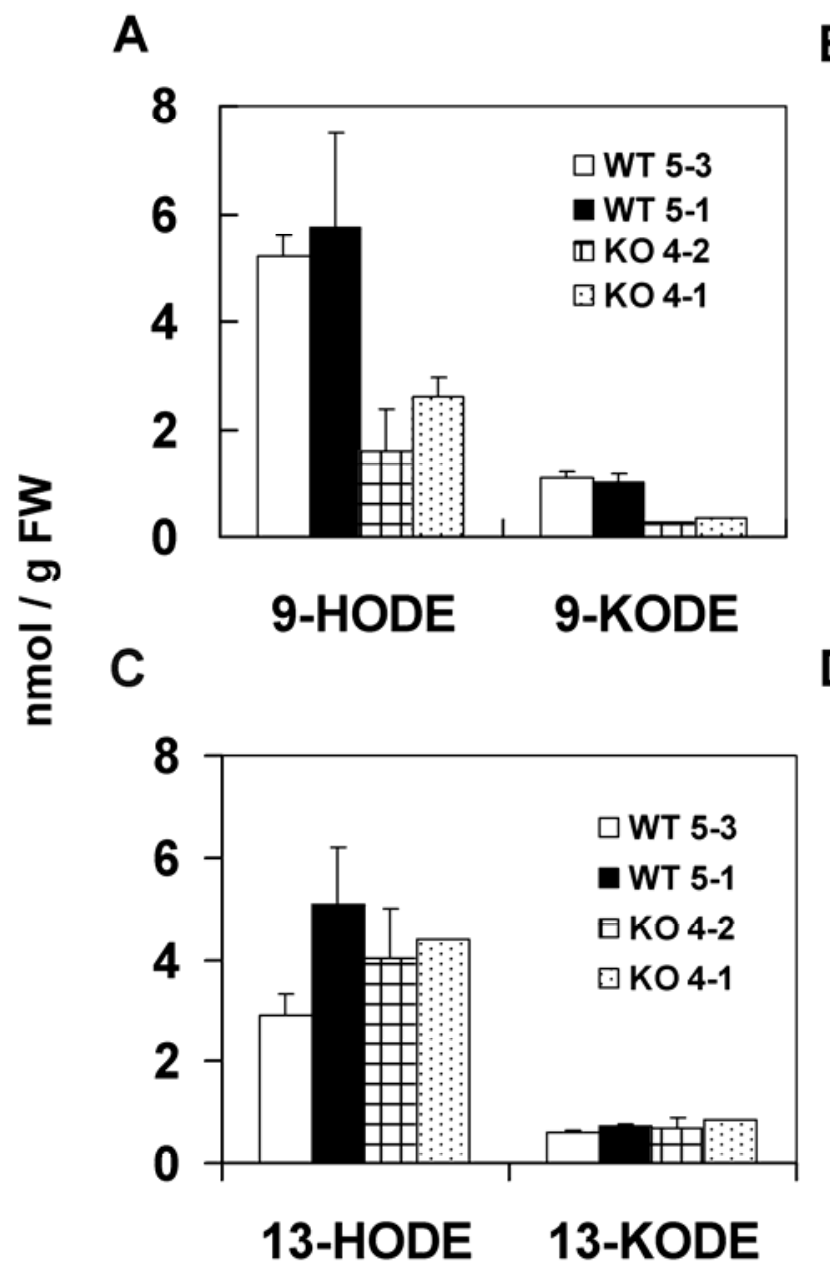

B
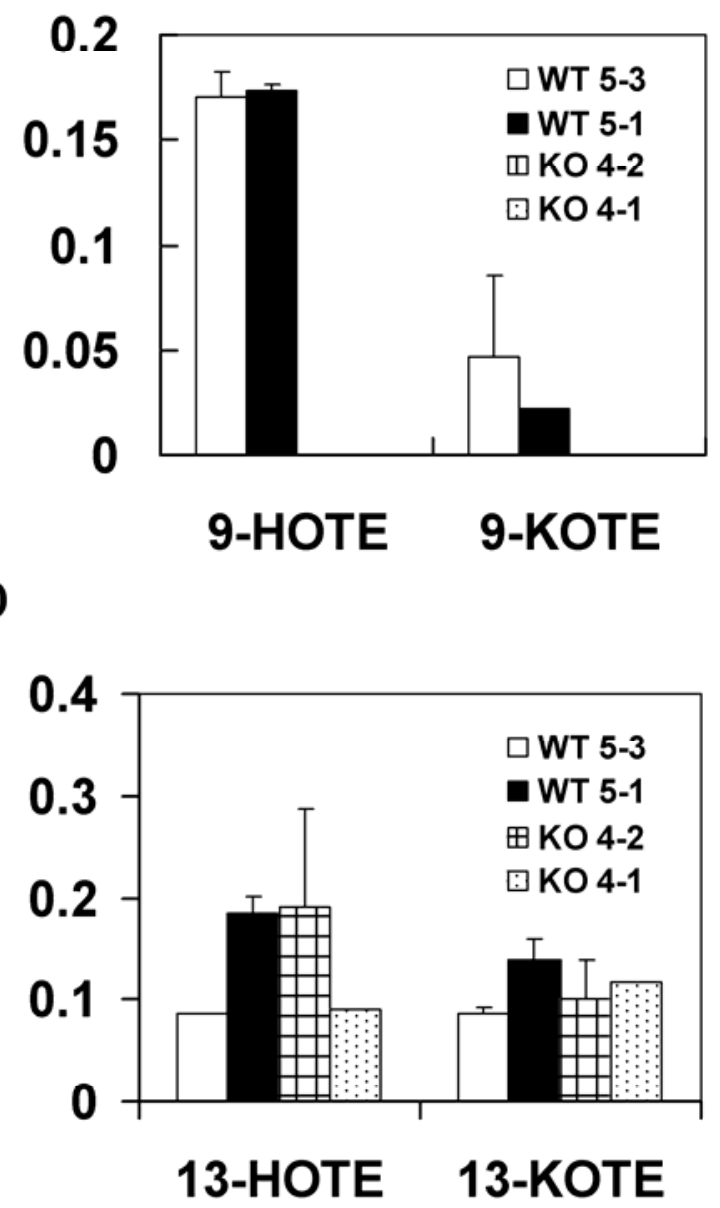

Fig. 2. Content of free 18:2-OH and 18:3-OH oxylipins extracted from the embryos in the 4-day-germinating lox3-4 mutant and wild-type seed determined by gas chromatography-mass spectrometry. WT, wild type; KO, Knock-Out. A, 9-HODE = (9S,10E,12Z)-9-hydroxy-10,12-octadecadienoic acid and 9KODE = ketodiene (9S,10E,12Z)-9-hydroxy-10,12-octadecadienoic acid. B, 9-HOTE = (9S,10E,12Z,15Z)-9-hydroxy-10,12, 15-octadecatrienoic acid and 9KOTE = ketodiene (9S,10E,12Z, 15Z)-9-hydroxy-10,12,15-octadecatrienoic acid. C, 13-HODE = (9Z,11E,13S,15Z)-13-hydroxy-9,11,15-octadecadienoic acid and 13-KODE = keto (9Z,11E,13S,15Z)-13-hydroxy-9,11,15-octadecadienoic acid. D, 13-HOTE = (9Z,11E,13S,15Z)-9-hydroxy-9,11,15octadecatrienoic acid and 13-KOTE = keto $(9 \mathrm{Z}, 11 \mathrm{E}, 13 \mathrm{~S}, 15 \mathrm{Z})-9$-hydroxy-9,11,15-octadecatrienoic acid. 
bands. During early stages of germination of wild-type seed, ZmLOX3 transcripts accumulated at the highest levels in embryos compared with mesocotyls, leaves, or roots (Fig. 1C). To establish whether $M u$ insertions in the lox3-4 allele resulted in complete loss of expression, total RNA was extracted from the embryos of 4-day-old germinating seed of $\mathrm{BC}_{4} \mathrm{~F}_{3}$ mutant and wild-type lines, and Northern analysis was performed. Transcripts of $Z m L O X 3$ were not detectable in the lox3-4 mutant (Fig. 1D), indicating that this allele is a strong loss-of-function allele of ZmLOX3. Morphologically, no difference was observed in kernel weight; however, the lox3-4 mutant displayed shorter roots, less root hairs, and reduced plant height compared to wild types (data not shown). This effect on the plant morphology and development is specifically associated with the disruption of $Z m L O X 3$ and is not due to this mutant's origin from the $M u$-active lines because $M u$ insertional mutants for several other LOX genes generated in our laboratory did not display any of the developmental phenotypes observed for the lox3-4 mutant.

\section{Levels of 9-LOX-derived oxylipins are reduced in the lox 3-4 mutant.}

Because transcripts of the $Z m L O X 3$ gene accumulated to the highest level (Fig. 1C) and were further induced by $F$. verticillioides infection (Wilson et al. 2001) in the embryos of 4-dayold germinating seed, we used embryos at this stage of seed- ling development to quantify and compare accumulation of diverse oxylipins in the lox3-4 mutant and wild type. The 9LOX products derived from C18:3, 9-HOTE, and 9-keto$10 E, 12 Z, 15 Z$-octadecatrienoic acid (9-KOTE) were drastically decreased, and C18:2-derived 9-HODE and 9-keto-10E,12Zoctadecadienoic acid (9-KODE) were notably reduced in the embryos of the mutants (Fig. 2A and B). Although 9-LOXderived oxylipins were reduced in the lox3-4 mutant, no significant differences of 13-LOX products derived from either C18:2 or C18:3 were observed between the embryos of wild types and lox3-4 mutants (Fig. 2C and D).

\section{$F$. verticillioides conidiation and fumonisin B1 production are reduced when grown on lox 3-4 mutant kernels.}

It was hypothesized that the ZmLOX3-mediated pathway is upregulated by $F$. verticillioides (Wilson et al. 2001) to promote susceptibility and induce production of conidia and fumonisins. To test this hypothesis, we carried out $F$. verticillioides kernel infection assays with the lox3-4 mutant and wild-type seed and measured $F$. verticillioides microconidia and fumonisin B1 (FB1) production 10 days after inoculation. Microconidia production on infected seed of lox3-4 mutants was 38\% lower than on wild-type kernels (Fig. 3A) and FB1 production was reduced almost 200-fold on lox3-4 mutant kernels compared with the levels on wild-type seed (Fig. 3B). Importantly, fungal vegetative growth was not affected by the lox3 mutation as

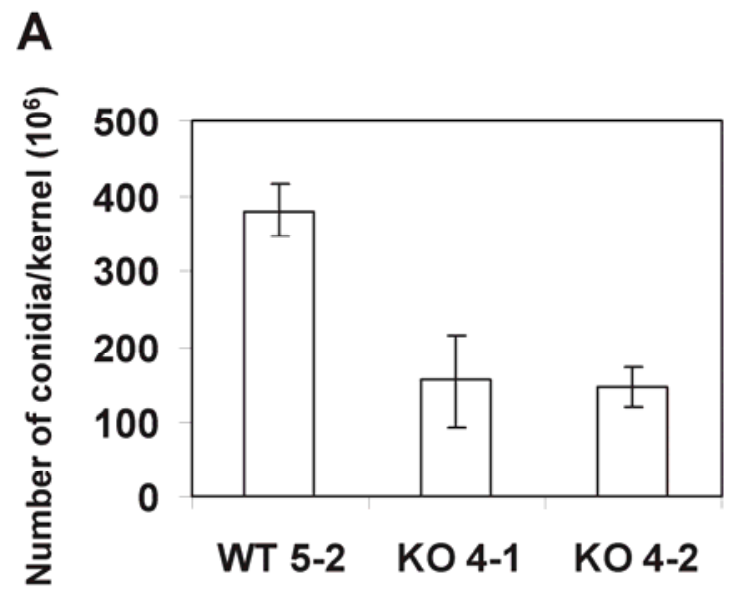

B
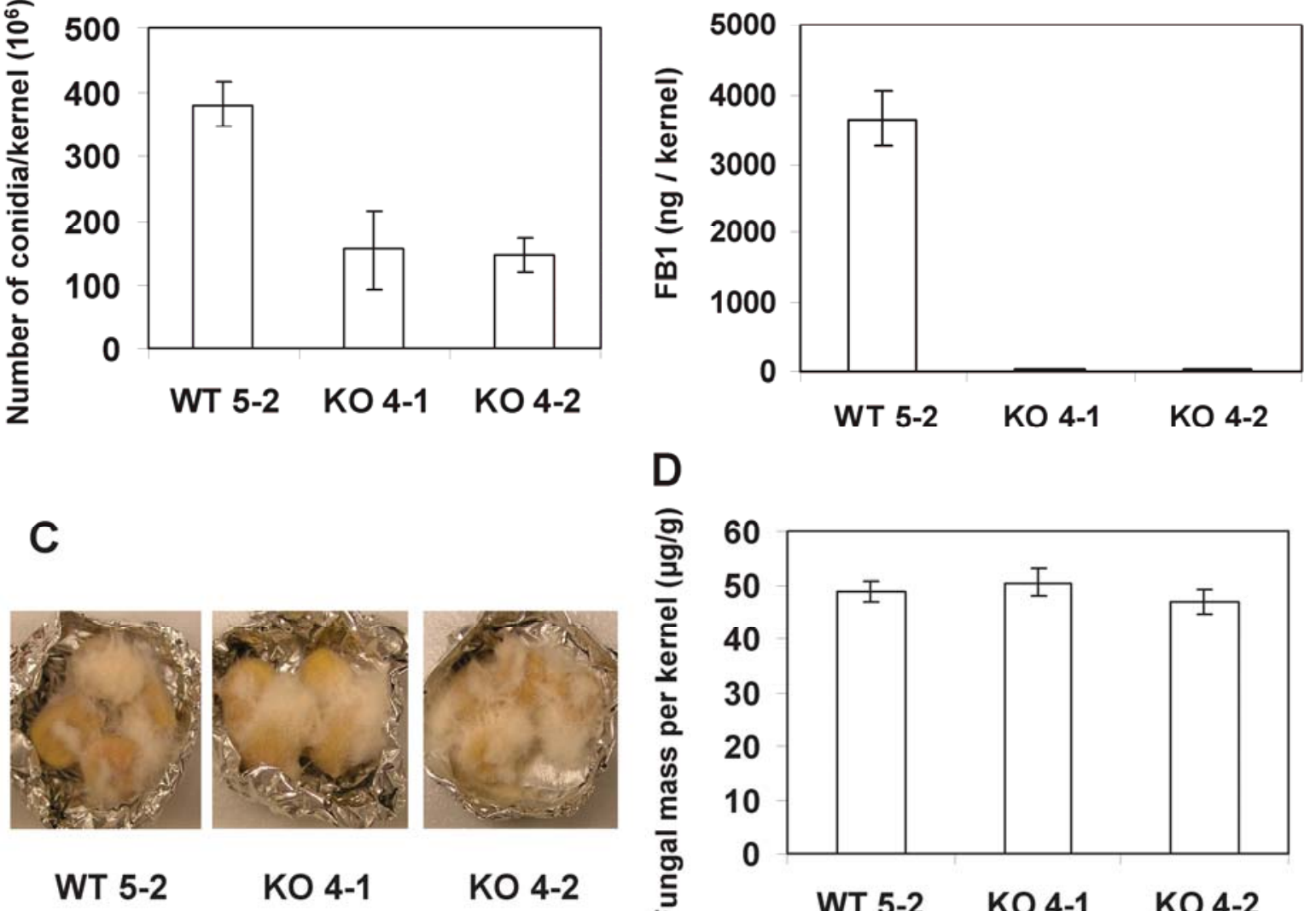

D

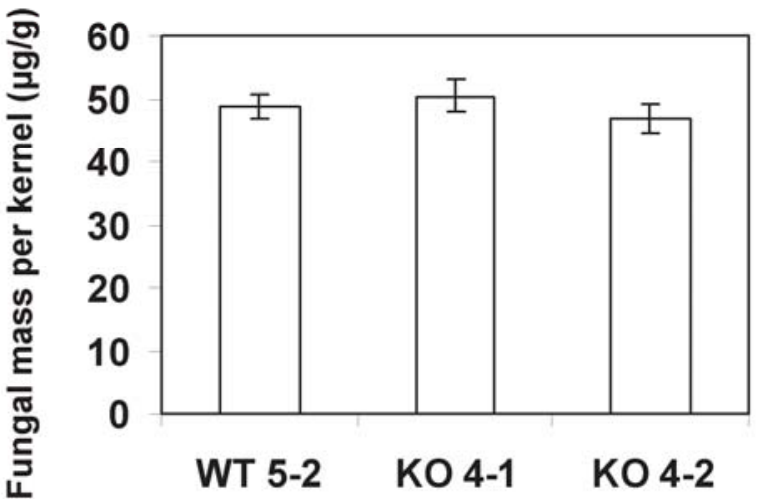

Fig. 3. Fusarium verticillioides A, conidiation and B, fumonisin B1 production are markedly inhibited when grown on kernels of maize lox3-4 mutants compared with the wild type (WT). A, Number of conidia produced on infected seed of maize lox3-4 mutants and near-isogenic WTs 10 days after inoculation. B, Quantification of fumonisin B1 was conducted 10 days after infection using high-performance liquid chromatography. Mean and standard error were calculated from two independent experiments (each containing four replicates with four kernels each). C, Colonization of WT and lox3-4 kernels with $F$. verticillioides. D, Fungal biomass of $F$. verticillioides grown on WT and lox3-4 kernels was determined by real-time polymerase chain reaction using $\beta$-tubulin gene-specific primers of $F$. verticillioides. Two independent experiments were performed with four biological replicates each containing four kernels infected with $10 \mu \mathrm{l}$ of conidial suspension $\left(1 \times 10^{6}\right.$ conidia per milliliter $)$ per $F$. verticillioides per seed. 
observed visually or measured by real-time PCR of genomic DNA extracted from infected kernels using $F$. verticillioides TUB2 gene-specific primers 10 days postinoculation (Fig. 3C and D).

\section{Disease severity of anthracnose leaf blight and} southern leaf blight is reduced in the lox3-4 mutant.

To determine whether ZmLOX3 contributes to susceptibility of maize to pathogenic fungi that infect organs other than seed, we tested levels of susceptibility of the lox3-4 mutant and wild-type near-isogenic lines (NILs) to $C$. graminicola and Cochliobolus heterostrophus, causal agents of anthracnose leaf blight (ALB) and southern leaf blight (SLB), respectively. Infection of leaves of 3-week-old seedlings with a virulent strain of $C$. graminicola showed that lesions on both mutant families tested were smaller than those found on the wild-type NILs (Fig. 4A, B, and C). Notably, upon infection with C. graminicola, the mutant leaves appear to accumulate higher levels of red anthocyanins surrounding the infection sites compared with the wild type (Fig. 4A). Similar to $F$. verticillioides sporogenesis, $C$. graminicola conidiation was decreased significantly when grown on infected lox3-4 mutant leaf disks (Fig. 4C). To test whether the observed decrease in conidiation was due to reduced growth of the fungus, we tested the levels of fungal mass by real-time PCR using $C$. graminicola-specific primers and genomic DNA extracted from the infected leaf disks at $120 \mathrm{~h}$ postculture. No difference in the fungal mass was detected on the leaf disks of wild types and mutants (Fig. 4D), indicating that reduced conidial production was not due to reduced fungal growth.

Northern blot analysis showed that ZmLOX3 expression was induced earlier and to a notably higher levels in response to infection by Cochliobolus heterostrophus in the leaves of a susceptible line compared with a near-isogenic resistant line (Fig. 5A), suggesting that ZmLOX3 may contribute to SLB disease progression. Field testing for the levels of susceptibility to Cochliobolus heterostrophus showed that race 0 of this pathogen caused severe disease symptoms on wild-type leaves, whereas substantially fewer symptoms were observed on lox34 leaves (Fig. 5C). On a scale 1 to 9 , with 1 being completely resistant and 9 being completely susceptible, the lox3-4 mutant displayed a consistent 1- to 1.5-point lower disease rating than the wild type through entire time course (Fig. 5B). Thus, collectively, our data indicate that disruption of $Z m L O X 3$ resulted in decreased severity of ALB and SLB diseases.

The lox3-4 mutant is more resistant to stalk rots caused by $\boldsymbol{F}$. verticillioides and $\boldsymbol{C}$. graminicola.

Next, we expanded our testing of the lox3 mutant to include diseases of maize stalk. Anthracnose stalk rot and Fusarium

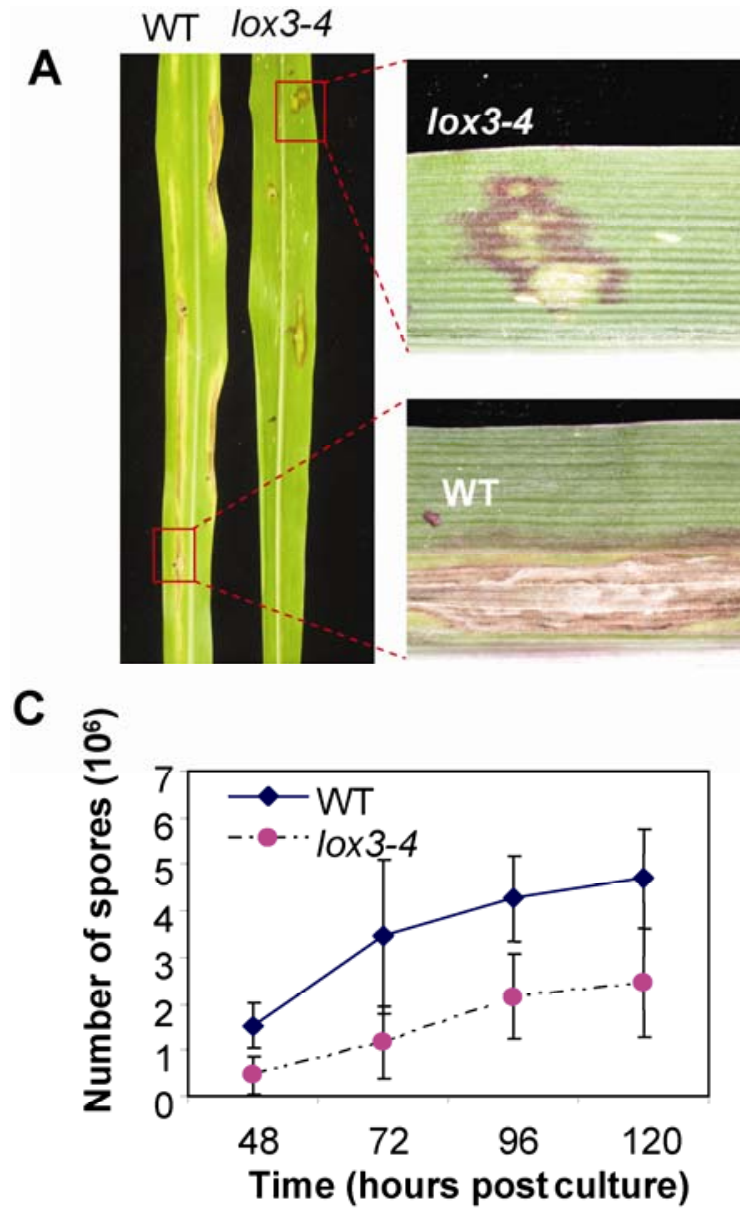

B

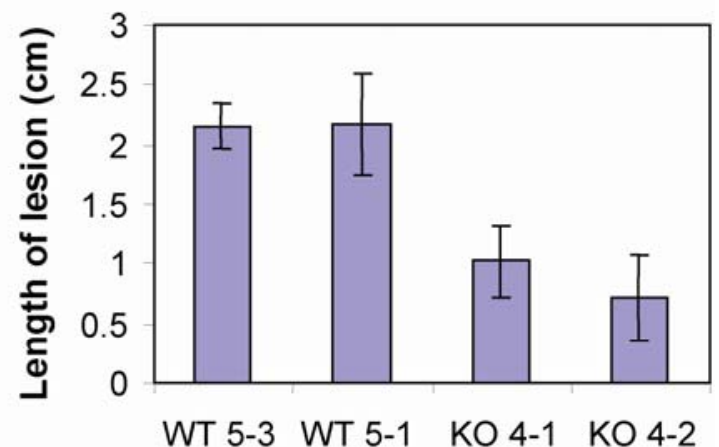

D

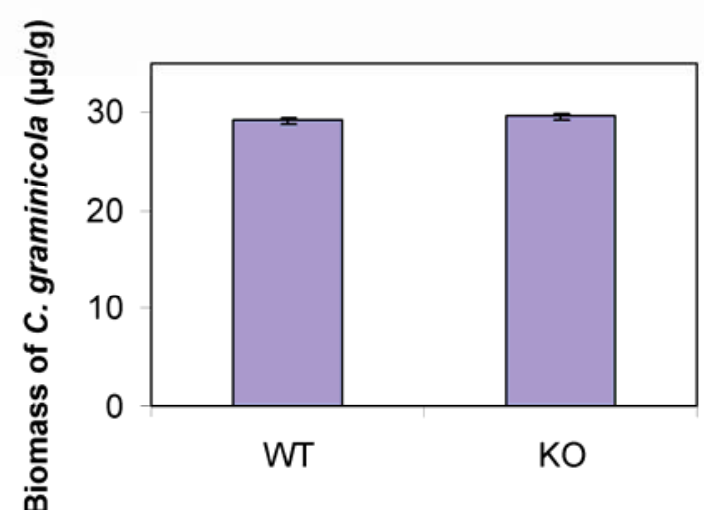

Fig. 4. The lox3-4 mutants are more resistant than wild type to anthracnose leaf blight caused by Colletotrichum graminicola. The third leaves of V3-stage maize seedlings were infected with $10 \mu \mathrm{l}\left(10^{6}\right.$ spores $\left./ \mathrm{ml}\right)$ of conidial suspension of $C$. graminicola strain M1.001. A, Disease symptoms on lox3-4 mutant and wild-type (WT) leaf in response to inoculation with $C$. graminicola. The leaves were excised and photographed 5 days after inoculation; lox3-4 mutants accumulate more anthocyanins around the infection site compared with the WT. B, Comparison of lesion size formed on infected leaves of the lox3-4 mutant and WT. The data are expressed as means \pm standard deviation (SD) from 20 replicates with five lesions per replicates. $\mathbf{C}$, Number of $C$. graminicola spores on the lox3-4 mutant versus WT leaves. The leaf disks were cut from leaves $48 \mathrm{~h}$ after infection with C. graminicola suspension $\left(10^{6} \mathrm{spores} / \mathrm{ml}\right)$ and cultured in petri dishes containing $5 \mathrm{ml}$ of sterile $\mathrm{H}_{2} \mathrm{O}$ to provide high-humidity conditions. The data are expressed as means $\pm \mathrm{SD}(n=10)$. D, Biomass of $C$. graminicola grown on lox3-4 mutant and WT leaves was measured by real-time polymerase chain reaction using genomic DNA extracted from leaf disks treated as described in C at $120 \mathrm{~h}$ postinfection. 
stalk rot, caused by $C$. graminicola and $F$. verticillioides, respectively, are among the most serious diseases of maize (Bergstrom and Nicholson 1999). RNA profiling by using the massively parallel signature sequencing (MPSS) technique showed that expression of $Z m L O X 3$ was induced in maize stems infected with $C$. graminicola approximately sixfold in an inbred line susceptible to anthracnose stalk rot, but only twofold in a resistant NIL (data not shown). To test whether this gene has a role in facilitating pathogenesis of fungi causing stalk rots, we inoculated stalks of lox3-4 mutant and wildtype NILs with $F$. verticillioides in a greenhouse and with $C$. graminicola under field conditions. Infection with $F$. verticillioides and $C$. graminicola caused severe deterioration of wildtype stalk tissues, whereas the lesion areas on the lox3-4 mu-
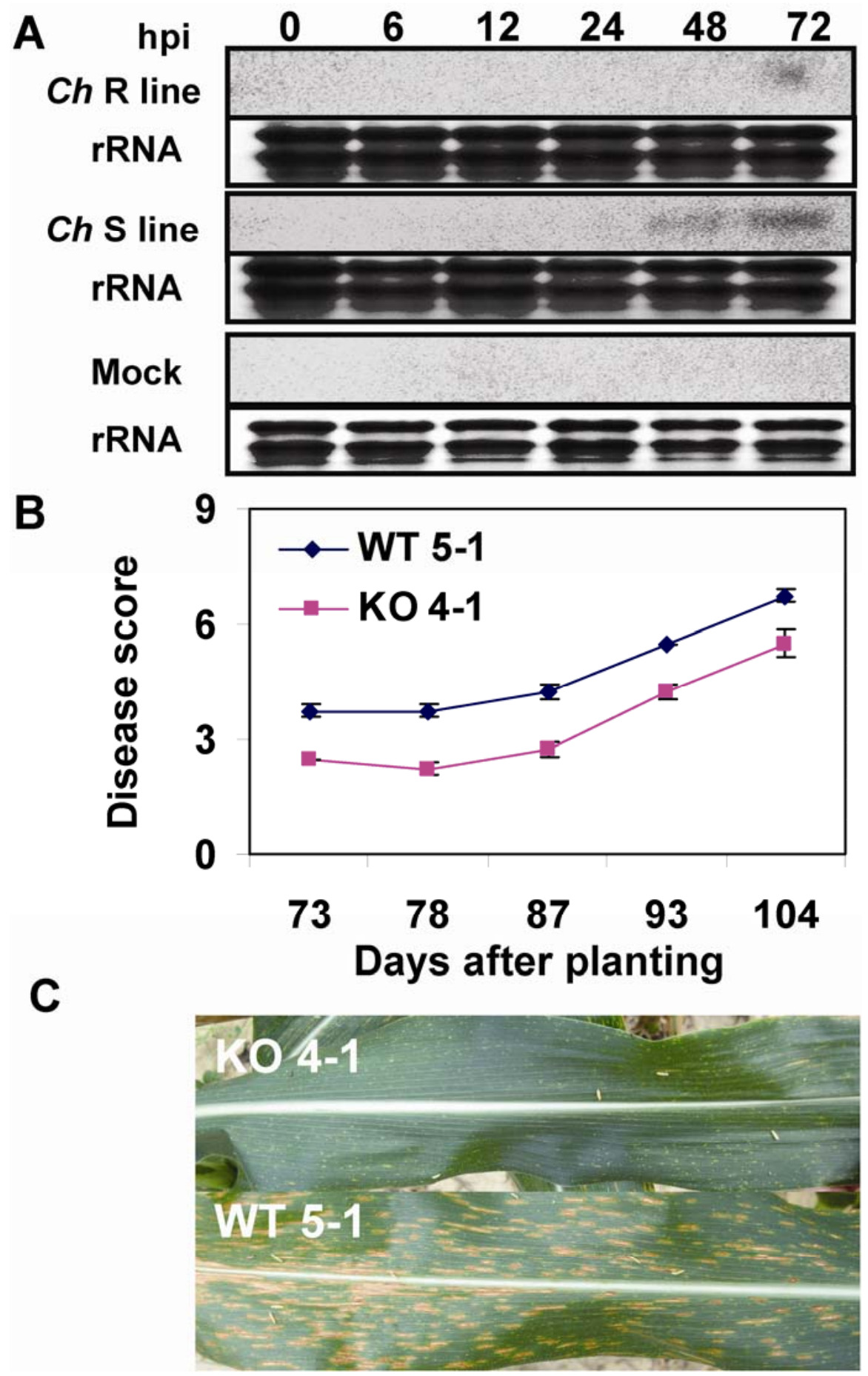

Fig. 5. The lox3-4 mutant is more resistant to southern corn leaf blight caused by Cochliobolus heterostrophus. A, Northern blot analysis of ZmLOX3 in response to infection with Cochliobolus heterostrophus. Corn homozygous lines for the rhml allele are resistant (R), while heterozygous lines (Rhm1/rhm1) are susceptible (S) to Cochliobolus heterostrophus $(\mathrm{Ch})$. Seedlings of these lines were treated with a conidial suspension and total RNA was extracted from leaves at selected times (hours) after infection. B and C, Field inoculations with Cochliobolus heterostrophus were performed with the lox 3-4 knockout 4-1 and the wild-type (WT) segregant 5-1 lines planted in side-by-side rows consisting of 12 plants per row. Two replications were planted in different parts of the field. The plants were rated for disease resistance periodically after flowering on a 1-to-9 scale with 1 being symptomless and 9 being dead. All the plants in a row were examined and an overall score was given to each row. B, The graph shows average ratings of the two replications at each time point. The range of scores also is indicated. $\mathbf{C}$, Typical ear leaf of a plant of line 4-1 (upper panel) and line 5-1 (bottom panel) infected with southern leaf blight. Pictures taken 86 days after planting. 
tant were much smaller (Fig. 6A and B). As shown by scoring the lesion area distribution, the lox3-4 mutant exhibited only $2.5 \%$ large lesions (lesion area $>200 \mathrm{~mm}^{2}$ ) caused by $F$. verticillioides and none by $C$. graminicola, in contrast to wild types which exhibited 39 and 50\% large lesions, respectively (Fig. $6 \mathrm{C}$ and D). The major proportion of the lesions found on lox3-4 mutant stalks were small lesions (lesion area $<50 \mathrm{~mm}^{2}$ ), $32.5 \%$ for $F$. verticillioides and $50 \%$ for $C$. graminicola, whereas there were fewer small lesions found on wild-type stalks (6.6 and $5.6 \%$ caused by $F$. verticillioides and $C$. graminicola, respectively).

\section{DISCUSSION}

Although existing reports implicated plant 9-LOXs and their metabolites in defense responses to pathogens, this study provides compelling evidence suggesting that certain fungal pathogens require expression of a specific host 9-LOX and its derivatives to facilitate pathogenesis, mycotoxin production, and their reproductive (e.g., conidia production) but not in-planta vegetative development. Previous studies using pharmacological approaches prompted a hypothesis that microbes may utilize host-produced 9-LOX-derived oxylipins to stimulate their developmental processes, including sporogenesis and mycotoxin production (Brodhagen and Keller 2006; Sagaram et al. 2006; Tsitsigiannis and Keller 2007). To test this hypothesis directly, we knocked out the Fusarium-inducible 9-LOX gene, ZmLOX3 (Wilson et al. 2001). Despite the fact that only one of several 9-LOXs identified in the maize genome was disrupted in these mutants, the accumulation of several 9-LOX derivatives was greatly reduced in the mutant embryos. These data confirmed that lox3-4 is a strong loss-of-function allele of $Z m L O X 3$ and suggested that this gene is the major 9-oxylipin producing LOX gene expressed in the germinating seed. ZmLOX3 appears to use both $\mathrm{C} 18: 2$ and $\mathrm{C} 18: 3$ acids as substrates because oxylipins derived from C18:3, 9S-HOTE, and 9S-KOTE were not detectable in the mutants, and C18:2-derived 9S-HODE and $9 S$-KODE were reduced to approximately $50 \%$ of the wild-type levels. It is likely that the remaining $50 \%$ of C18:2 derivatives are synthesized by a closely related 9-LOX isoform
A

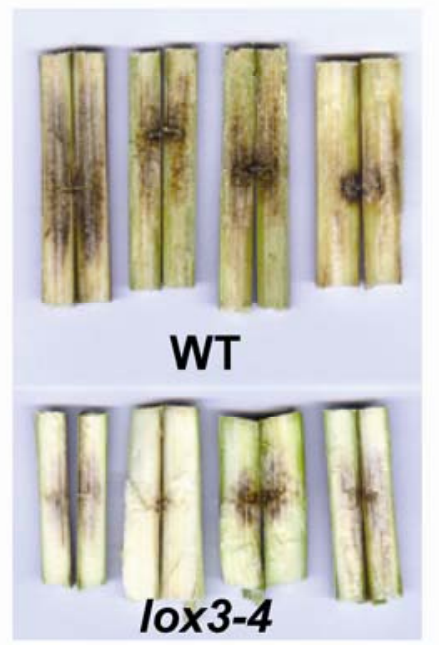

B

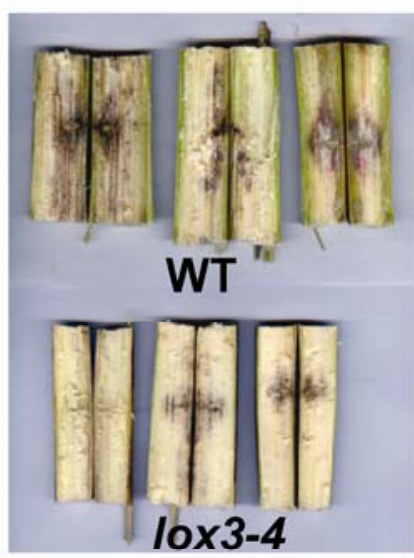

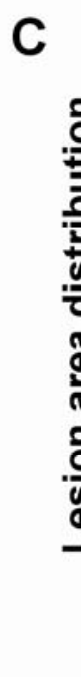
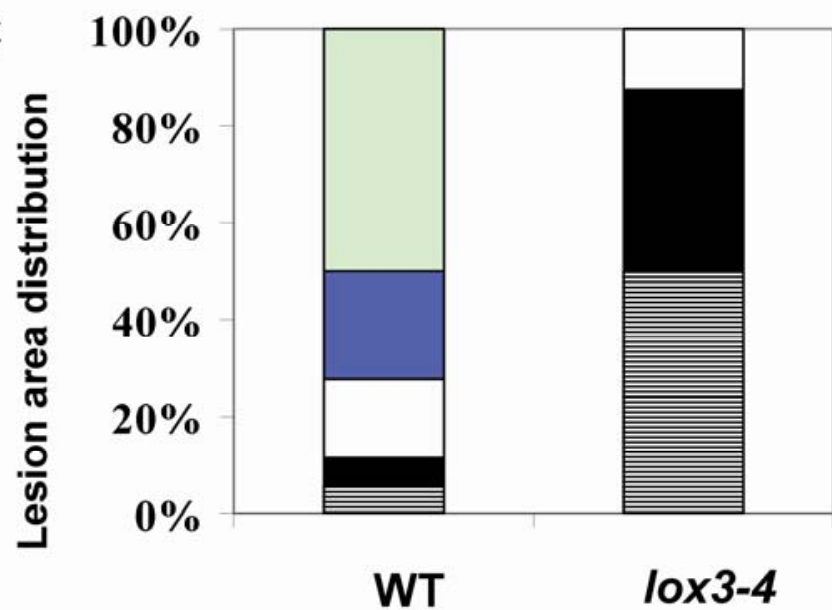

$\square>200 \mathrm{~mm}^{2} \square 151-200 \mathrm{~mm}^{2} \square 101-150 \mathrm{~mm}^{2}$

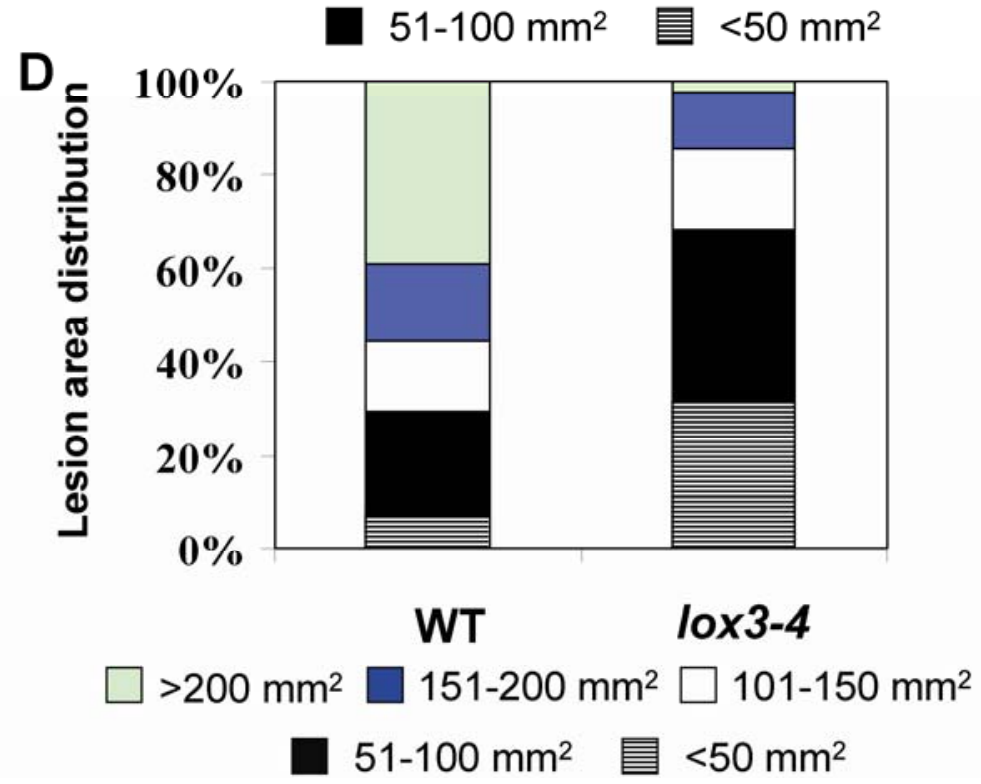

Fig. 6. Stalk rot disease symptoms on wild-type (WT) and lox3-4 mutant caused by Fusarium verticillioides and Colletotrichum graminicola. Left panels, the pictures were taken 10 days postinfection with $\mathbf{A}, F$. verticillioides and $\mathbf{B}, C$. graminicola spore suspension culture, and the lesions were scanned and analyzed with ImageJ software. Right panels, scoring of symptoms by measuring lesion area in five classes: $<50,50$ to 100,101 to 150 , 151 to 200 , and $>200 \mathrm{~mm}^{2}$. In all, C, 40 mutant and $42 \mathrm{WT}$ internodes were infected with $F$. verticillioides in a greenhouse and D, 18 mutant and 16 WT internodes were infected with $C$. graminicola in the field. The experiments were repeated twice and similar results were obtained. 
or isoforms known to be induced during seed germination at the same time points as $Z m L O X 3$ (Wilson et al. 2001).

Analysis of the lox3-4 mutants clearly demonstrated that inactivation of $\mathrm{ZmLOX} 3$ resulted in drastically reduced levels of conidia and fumonisin production on kernels by $F$. verticillioides, although it did not lead to any detectable reduction of fungal vegetative growth. These findings suggest that the host ZmLOX3-mediated production of oxylipins is required for reproductive development and secondary metabolism but not vegetative growth in $F$. verticillioides. Furthermore, the effect of $\mathrm{ZmLOX} 3$ on fungal pathogenesis seems to be more general because this isoform is required for pathogenic development (e.g., ability to colonize host tissue and produce spores) of the fungi affecting other plant organs, including leaves and stems. Specifically, we investigated whether ZmLOX3 is contributing to plant susceptibility to $C$. graminicola, a causal agent of ALB and anthracnose stalk rot diseases of maize. Quite remarkably, disruption of $Z m L O X 3$ resulted in significantly reduced disease severity of ALB and decreased conidiation of $C$. graminicola. It is important to note that, similar to $F$. verticillioides, when C. graminicola growth was restricted to the infected leaf disks its biomass was not affected by the lox3-4 mutation. Furthermore, the lox3-4 mutant is significantly less susceptible to stalk rots caused by $F$. verticillioides and $C$. graminicola and to the SLB pathogen Cochliobolus heterostrophus. Taken together, our data indicated that a 9-LOX oxylipin pathway mediated by ZmLOX3 may be utilized by certain fungal pathogen species to regulate pathogenesis, sporulation, and secondary metabolism (e.g., mycotoxin production) but not vegetative growth. Surprisingly, preliminary data suggests that A. flavus pathogenesis is not impacted negatively by the lox 3 mutation and that A. flavus may utilize a different specific 9-LOX to induce sporulation and aflatoxin production (X. Gao and M. Kolomiets, unpublished data). A detailed phenotypic, molecular, and oxylipin analysis of the lox3 mutant's response to $A$. flavus infection is currently underway in our laboratory and, once completed, will be compared with that of $F$. verticillioides.

It is important to emphasize that the observed negative effects of lox3-4 mutation on pathogenicity of the three fungi studied cannot necessarily be generalized to all 9-LOXs or to all fungal pathogens. In fact, antisense disruption of a tobacco 9LOX gene resulted in the loss of HR-mediated resistance to an oomycete $P$. parasitica (Rance et al. 1998). Moreover, using macroarray analysis, expression of several putative 9-LOXs have been shown to be induced earlier and to notably higher levels by Colletotrichum trifolii infection of a Medicago truncatula cultivar that was resistant to ALB compared with a sus-

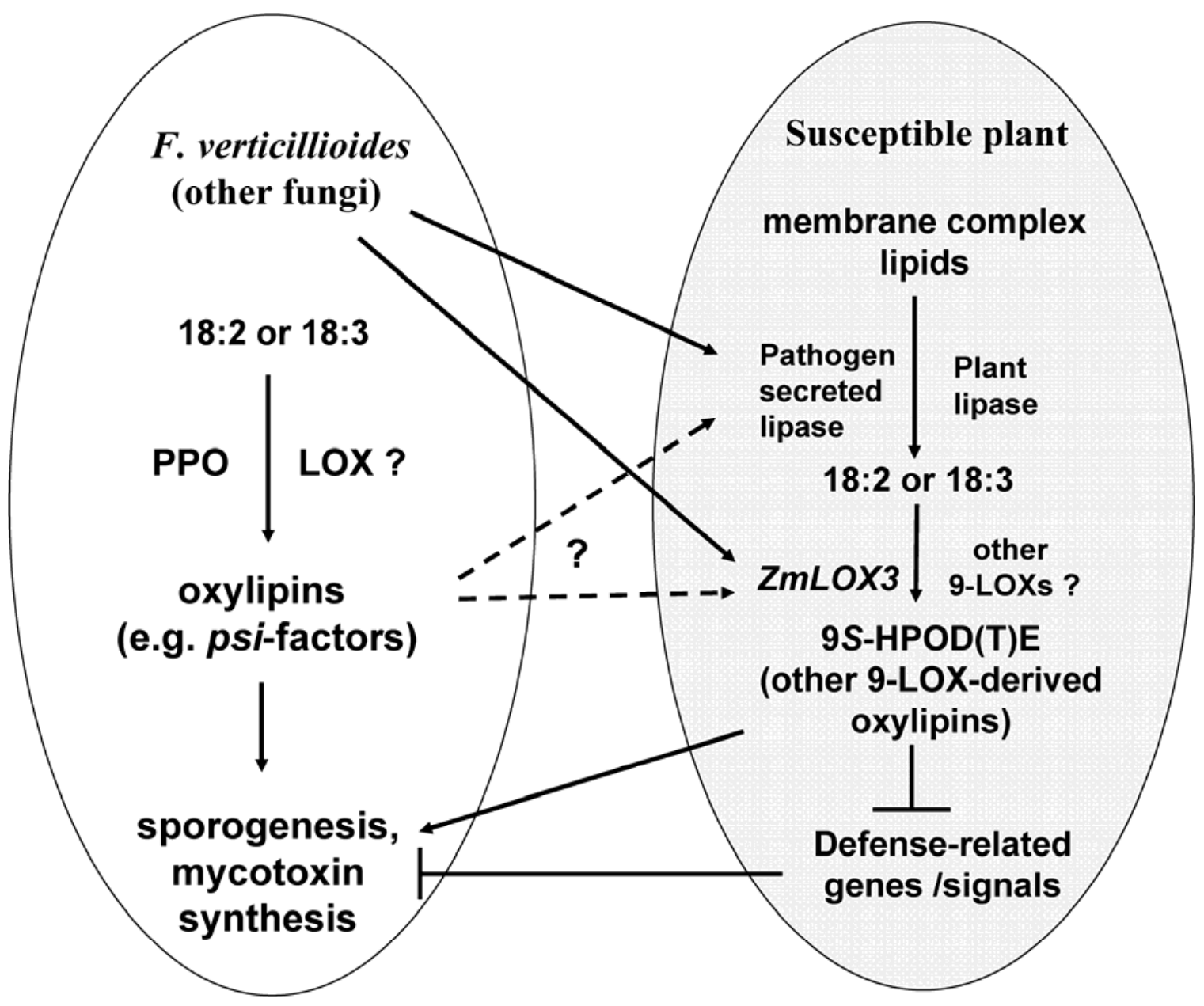

Fig. 7. Working model for the involvement of 9- and 13-lipoxygenase (LOX) pathways and their derived oxylipins in the interaction between maize and fungal pathogens. Both plants and fungi produce oxylipins. Fungal oxylipins are called psi factors and are required for conidia and mycotoxin production (Brodhagen and Keller 2006). Plant 9-LOX-derived oxylipins are implicated in development and defense-related processes. Fungal pathogens either secrete their own lipase (Voigt et al. 2005) or induce a host lipase (La Camera et al. 2005) to release free polyunsaturated fatty acids from cellular membranes. We hypothesize that plant 9-LOXs and their derivatives are utilized by fungi to stimulate reproductive development and mycotoxin production. PPO, psi-producing oxygenase; 9S-HPODE, $(9 S, 10 E, 12 Z)$-9-hydroperoxy-10, 12-octadecadienoic acid; 9S-HPOTE, (9S, 10E, 12Z, 15Z)-9-hydroperoxy-10, 12, 15-octadecatrienoic acid. Solid arrow: known interaction; dashed arrow: hypothesized interaction. 
ceptible cultivar (Torregrosa et al. 2004), supporting a defenserelated role for these specific LOXs.

The results of this study suggest that, in addition to a defense-related function of 9-LOX metabolites, certain 9-LOXs and their products may contribute to host susceptibility; therefore, an alternative concept is needed for the role of these lipid derivatives in some (but not all) plant-pathogen interaction systems. Previous evidence suggests that polyunsaturated fatty acids, including the LOX substrate C18:2 and its plant derivative 9S-HPODE, stimulated sporogenesis and mycotoxin production (Calvo et al. 1999; Brodhagen and Keller 2006; Burow et al. 1997). In this regard, plant oxylipins seem to have an effect similar to fungal oxylipins which function as potent regulators of several developmental pathways in fungi, such as sporulation and mycotoxigenesis (Brodhagen and Keller 2006). Deletion of oxylipin-producing genes such as ppo caused the reduction of conidia and mycotoxin production, as well as failure to colonize peanut seed (Tsitsigiannis and Keller 2006). Furthermore, disruption of ppo genes in F. sporotrichioides also resulted in reduction of mycotoxin and spore production (McDonald et al. 2004). Due to the structural and biosynthetic similarities of psi factors to plant oxylipins, it was hypothesized that seed linoleic acid and its derivatives could be mimicking or interfering with endogenous psi factors and, thus, directing developmental processes in fungi (Champe and Elzayat 1989; Champe et al. 1987; Mazur et al. 1991; Tsitsigiannis et al. 2004a; Tsitsigiannis and Keller 2007). Our study presents strong evidence to support this hypothesis by showing that deletion of the maize 9-LOX gene, ZmLOX3, resulted in significant reduction of sporogenesis and decreased disease severity caused by the three pathogenic fungi tested. Interestingly, it has been observed that $F$. verticillioides does not produce much FB1 on synthetic medium compared with kernels (Shim and Woloshuk 2001). Our data suggest that one possible reason for such preference toward lipid-rich tissues is that host lipids, more likely their oxylipin derivatives, are signals required for triggering pathogenic development in mycotoxigenic fungi.

It could be argued that mutation of $Z m L O X 3$ may have increased the production of some unidentified antifungal metabolites and, therefore, suppressed conidiation and mycotoxin production. Our data, however, clearly demonstrated that the vegetative growth of at least two fungi, $F$. verticillioides and $C$. graminicola, was not affected by the lox3-4 mutation. On the other hand, one cannot exclude the possibility of interactions between different branches of the LOX pathway; for example, disruption of 9-LOX genes may result in overexpression of 13LOX genes or increased levels of 13-LOX derivatives. This possibility, however, was not confirmed by oxylipin profiling of the noninfected germinating seed that showed no significant difference in the level of oxylipins derived from the 13-LOX pathways between wild types and lox3-4 mutants. Nevertheless, profiling of major defense hormones, oxylipins, and defense gene transcripts of kernels in response to $F$. verticillioides and of leaf to $C$. graminicola infections is currently underway to provide more detailed insights into the biochemical and molecular mechanisms underpinning the phenotypes of lox3-4 mutants.

Based on the finding that exogenously applied plant 9oxylipins stimulate production of conidia and mycotoxins (Brodhagen and Keller 2006), and the results presented here, we propose a model for the role of ZmLOX3 in the oxylipinmediated cross-talk between plants and pathogens (Fig. 7) in which certain fungal pathogens induce expression of specific plant 9-LOXs to stimulate production of plant 9-LOX-derived oxylipins. We propose that these plant oxylipins mimic the action of the pathogen-synthesized oxylipins (e.g., psi factors) by inducing production of conidia and mycotoxins. Alternatively, it is possible that expression of specific 9-LOX genes such as $Z m L O X 3$ in response to pathogen invasion may result in suppression of other defense signal transduction pathways, as has been shown for the antagonistic interaction between JA (derived from the action of a 13-LOX) and salicylic acid (Dong 1998). It is possible that fungal oxylipins may act as signals to induce expression of specific plant 9-LOXs. Recent evidence indicates that pathogen virulence not only is determined by expression of the pathogen's own genes but also requires host factors to facilitate normal disease development. For example, it was shown that silencing of a patatin-like lipid acyl hydrolase (AtPLP2) gene from Arabidopsis enhanced host resistance to fungal and bacterial pathogens, whereas overexpression of this gene caused enhanced disease symptoms, suggesting that this Arabidopsis lipid-metabolizing enzyme and its derivatives facilitate host colonization by pathogens ( $\mathrm{La}$ Camera et al. 2005). Because Arabidopsis PLP2 protein exhibited pronounced phospholipase and galactolipase activities and, thus, may be involved in the release of free polyunsaturated fatty acids from membrane-associated complex lipids, this enzyme may provide substrates for a 9-LOX-mediated production of oxylipins that, similar to the ZmLOX3-derived oxylipins, may be required for normal virulence of fungal pathogens (Fig. 7). Instead of manipulating the plant-encoded lipases, fungi may utilize yet another strategy to modulate plant lipid metabolism by secreting its own lipase into the plant cell. This possibility has been clearly demonstrated in F. graminearum, another mycotoxin-producing fungal pathogen of maize (Voigt et al. 2005). In that study, deletion of an extracellular lipase FGL1 resulted in complete inability of this pathogen to colonize maize ears, suggesting a key significance of this lipidmetabolizing enzyme in the processes of pathogenesis.

In summary, our findings provide compelling evidence that host oxylipin pathways may be important for successful colonization by certain fungal pathogens. We hypothesize that these pathogens may require the host oxylipin pathways in order to facilitate pathogenesis, reproductive development, and biosynthesis of mycotoxins. Furthermore, our data provide strong support for the idea that oxylipins derived from either plants or their pathogens can mediate a cross-talk between pathogens and their host plant (Brodhagen and Keller 2006; Sagaram et al. 2006).

\section{MATERIALS AND METHODS}

\section{Generation of lox3 mutants.}

The lox3 mutants were isolated by using a reverse genetics resource generated at Pioneer Hi-Bred International, the socalled trait utility system for corn, which is essentially a large $M u$ insertional population of approximately 42,000 mutant individuals. This population was generated by crossing $\mathrm{Mu}$ active pollen parents with selected public lines as females. The resulting $F_{1}$ individuals were self-pollinated to generate $F_{2}$ seed that segregate for $M u$ insertions in individual genes, thus establishing a library of transposon-mutagenized seed. To identify insertions in individual LOX genes, this $M u$-active population was screened by PCR essentially as described by Bomblies and associates (2003), with minor modifications. $M u$ insertions in the $Z m L O X 3$ gene were identified by PCR using a $M u$ terminal inverted repeat primer 9242 (5'-AGA-GAA-GCCAAC-GCC-AWC-GCC-TCY-A-3') in combination with either of the ZmLOX3-specific primers: 41541-F CGC-CGT-AGTTCT-TCC-TCA-AGA-CAA-TCA-C-3', 41542-R 5'-CGA-CAGTCG-GCT-ATC-CGA-GTT-GG-3', 41543-F 5'-TCG-TTG-ACAGCA-TCA-GCG-AGT-TCC-TC-3', 41545-F 5'-GAC-TCC-TTCCAG-GAC-ATC-ATC-AAC-CTG-T-3'，41546-R 5'-CTG-GTG- 
GCG-TAG-ATG-AAG-TTG-CCC-T-3'; 51473-F 5'-AAC-AGCCTG-GAG-GGC-AAC-TTC-ATC-TAC-3', and 51474-R 5'AGG-AGT-GGC-TGG-ACA-GGA-TCT-CCA-3'. Initial screening of the mutant library identified 24 PCR-positive individuals. To ensure germinal transmission of $Z m L O X 3 M u$-insertional alleles, $F_{2}$ transmission testing was performed on those individuals harboring putative mutant alleles. For this, genomic DNA was isolated from dry kernels representing the $F_{2}$ mutant populations and amplified with appropriate primers. Only five $\mathrm{F}_{2}$ individuals, representing four different alleles, were identified with $M u$ insertion events that were germinally transmitted. PCR fragments flanking both sides from the insertion sites were cloned into the pCR2.1 TOPO vector (Invitrogen, Carlsbad, CA, U.S.A.) and sequenced to identify the precise location of $M u$ insertions. Original mutant alleles are likely to contain different numbers of $M u$ elements found elsewhere in their genome. To remove these unrelated mutations, we backcrossed the original mutant alleles to the inbred line B73 four times $\left(\mathrm{BC}_{4}\right)$ and self-pollinated the $\mathrm{BC}_{4}$ individuals. This resulted in the generation of near-isogenic individuals that are either mutants, heterozygotes, or wild types at the ZmLOX3 locus at the $\mathrm{BC}_{4} \mathrm{~F}_{2}$ genetic stage. This genetic stage is suitable for assessing the effect of the LOX gene knockouts on the host interactions with pathogens. To identify homozygous mutant and wild-type plants, the segregating $\mathrm{BC}_{4} \mathrm{~F}_{2}$ populations were genotyped first by PCR with primer 9242 and the gene-specific primers and later confirmed by Southern blotting analysis described in detail below. The homozygous wild-type or mutant individuals were self-pollinated to produce $\mathrm{BC}_{4} \mathrm{~F}_{3}$ and $\mathrm{BC}_{4} \mathrm{~F}_{4}$ seed that was used in all of the plant-pathogen interaction experiments described in this article. We attempted to generate additional mutant alleles for the $Z m L O X 3$ gene by generating deletion derivatives of the existing alleles utilizing the site-selected transposon mutagenesis approach (Das and Martienssen 1995). Specifically, we screened approximately 3,000 $\mathrm{F}_{1}$ progeny derived from progenitor $M u$-insertional alleles by PCR using primers from $M u$-conserved regions and the target gene. Unfortunately, no new mutant derivative was identified in these experiments.

\section{Infection of leaves with $C$. graminicola.}

For inoculation with $C$. graminicola, lox3-4 mutants and near isogenic wild-type seeds were grown at approximately 25 to $28^{\circ} \mathrm{C}$ in commercial soil (Metro-Mix 366; Scotts-Sierra Horticultural Products, Marysville, OH, U.S.A.) under $14 \mathrm{~h}$ of daylight with $120 \mu \mathrm{mol} \mathrm{m} \mathrm{m}^{-2} \mathrm{~s}^{-1}$ (Quantum Meter; Apogee Instruments, Logan, UT, U.S.A.). The seedlings were grown in long conical tubes $(20.5$ by $4 \mathrm{~cm})$ for 2 to 3 weeks until they had three fully expanded leaves (V3 developmental stage). $C$. graminicola 1.001 was cultured on potato dextrose agar and the conidia suspension for infection was prepared as described by Thon and associates (2002). For inoculation, leaves of seedlings were laid down on the wet paper towel in the trays ( 75 by 60 by $7 \mathrm{~cm}$ ). The third leaves were held carefully on the surface of paper towel using clear stretch tape and were drop inoculated with $10 \mu \mathrm{l}$ of conidial suspension $\left(10^{6}\right.$ conidia $\left./ \mathrm{ml}\right)$, with five droplets per each leaf in the middle part $5 \mathrm{~cm}$ distal to the tip and basal of the leaf blade. The trays subsequently were sealed with PressInSeal Saran wrap (The Glad Products Company, Oakland, CA, U.S.A.) to form a humid chamber. The seal then was removed $24 \mathrm{~h}$ after inoculation and the plants were allowed to dry before being returned to upright position. The inoculated plants were grown under the same conditions as those prior to infection. The disease symptoms were photographed and the lesion length was measured at 5 days after inoculation. Mock infection with distilled water was used as a control.
For C. graminicola conidiation assays, the third leaves of lox3-4 mutant and wild-type seedlings were inoculated as described above. Leaf disks ( $8 \mathrm{~mm}$ in diameter) were excised with a cork borer from the control or infected leaves $48 \mathrm{~h}$ after infection and cultured in petri dishes with two layers of Whatman filter paper wetted with $10 \mathrm{ml}$ of sterile distilled water, under $14 \mathrm{~h}$ of light and $10 \mathrm{~h}$ of dark at 25 to $28^{\circ} \mathrm{C}$. The leaf disks ( $10 \mathrm{~mm}$ in diameter) were harvested carefully at designated time points with a cork-borer and transferred into 0.5$\mathrm{ml}$ microtubes containing $100 \mu \mathrm{l}$ of sterile $\mathrm{dH}_{2} \mathrm{O}$. After vortexing for $10 \mathrm{~s}$, the spore suspension was immediately counted under an Olympus microscope (BX41TF) with a hemacytometer. The experiments were repeated at least three times and consistent results were obtained. The data were expressed as the means of 10 leaf disks for each treatment.

\section{Stalk rot assays.}

The stalk rot assay was conducted as described by Thon and associates (2002), with some modifications. Briefly, stalks of 10-week-old wild-type or lox3-4 mutants (1 week postpollination) were wounded with a sterile needle $(1 \mathrm{~cm}$ in depth) and were infected with conidial suspension of either $C$. graminicola or $F$. verticillioides prepared as described above. A cotton swab soaked with the conidial suspension (approximately 150 $\mu l$ of $1 \times 10^{6}$ spores $/ \mathrm{ml}$ ) was placed on the wound site and subsequently sealed with Parafilm to form a humidity chamber. For infection with $C$. graminicola, we used plants grown in a field. Plants grown in a greenhouse with a temperature of 22 to $28^{\circ} \mathrm{C}$ were used for infection with $F$. verticillioides. The stalk rot assay was conducted on 8 individual plants for $C$. graminicola and 14 plants for $F$. verticillioides infection in each treatment. Two to three internodes were infected on each plant. Infection was allowed to proceed for 10 days and stalks were split longitudinally for examination of disease symptoms. The lesion area was scanned and analyzed by ImageJ software (ImageJ 1.36b; Wayne Rasband, NIH, Bethesda, MD, U.S.A.). Consistent results were obtained in two independent replicate experiments.

\section{Kernel assay for conidia and fumonisin production by $\boldsymbol{F}$. verticillioides.}

For inoculum production, F. verticillioides 7600 (M3125; Fungal Genetics Stock Center, University of Missouri, Kansas City, KS, U.S.A.) was grown on potato dextrose agar (B\&D, Sparks, MD, U.S.A.) at $28^{\circ} \mathrm{C}$. To examine the conidiation and fumonisin production, $F$. verticillioides was grown on surfacesterilized maize kernels in a petri dish under high relative humidity. The pericarp of each kernel was wounded with a sterile needle, and a $10-\mu$ droplet of conidia suspension $\left(1 \times 10^{6}\right.$ conidia per milliliter) was applied to the wound site. After 10 days of incubation at $25^{\circ} \mathrm{C}$, fumonisins were extracted from kernels and analyzed by high-performance liquid chromatography (HPLC) (Shim and Woloshuk 2001). HPLC analyses were performed independently in two laboratories, the Office of Texas State Chemist (College Station, TX, U.S.A.) and C. P. Woloshuk's laboratory at Purdue University (West Lafayette, IN, U.S.A). Conidiation assays were performed as described by Shim and Woloshuk (2001). Two independent experiments were performed with four biological replicates each containing four kernels infected with $10 \mu$ of conidial suspension $(1 \times$ $10^{6}$ conidia per milliliter) F. verticillioides per kernel.

\section{Fungal biomass assays.}

We estimated the biomass of $F$. verticillioides in maize kernels by measuring fungal DNA following previously described methods (Alkan et al. 2004). The real-time PCR experiments were performed in a Cepheid Smart Cycler Real-Time PCR 
System (Sunnyvale, CA, U.S.A.). The DNA samples were extracted from $F$. verticillioides-infected kernels and were used as a template for real-time PCR analysis with $F$. verticillioides $\beta$-tubulin (TUB2, GenBank U27303) gene-specific primers 5' CAG-CGT-TCC-TGA-GTT-GAC-CCA-ACA-G-3' and 5'CTG-GAC-GTT-GCG-CAT-CTG-ATC-CTC-G-3'. The biomass of $C$. graminicola grown on lox3-4 mutant and wild-type leaves also was determined by real-time PCR. Briefly, the leaf disks were prepared as for the conidiation assay described above, and DNA was extracted from 10 leaf disks. The primers for the C. graminicola high mobility group gene (HMG) were provided by L. Vaillancourt (University of Kentucky, Lexington, KY, U.S.A.): HMGgramF, 5'-CGT-ATA-TTC-TCT-ACCGCA-AGG-3' and HMGgramR, 5'-GGG-GGT-GCA-GTTTGT-TAT-G-3'. For amplification and quantification of target fungal DNA, the QuantiTect SYBRGreen RT-PCR kit (Qiagen, Valencia, CA, U.S.A.) was used following the manufacturer's suggested protocol, except the annealing temperature was $55^{\circ} \mathrm{C}$.

\section{Inoculation with Cochliobolus heterostrophus and field trials for SLB evaluation.}

For the Northern blot analysis of $Z m L O X 3$ gene expression in response to Cochliobolus heterostrophus, we used total RNA prepared for the experiments described by Zhang and associates (2005). SLB resistance evaluations were performed in 2006 at the North Carolina State University, Central Crops Research Station located at Clayton, NC, using previously reported methods for artificial inoculation (Carson et al. 2004). Briefly, experimental and border plots were inoculated at the four- to six-leaf stage by placing approximately 20 grains of a sorghum seed culture of Cochliobolus heterostrophus race $\mathrm{O}$, isolate 2-16Bm (Carson 1998) in the leaf whorl of every plant in every plot (including border plots). Plots were $2 \mathrm{~m}$ in length with a $0.6-\mathrm{m}$ alley at the end of each plot. Inter-row spacing was $0.97 \mathrm{~m}$. Twelve lox3-4 wild-type line 5-1 and mutant line 4-1 seed per plot were planted and rows were not thinned. The plots were planted side by side. Two plots of inbred border were planted on all sides of the experiment. Overhead irrigation was used as needed to ensure satisfactory plant growth. Standard fertilizer and herbicide regimes for central North Carolina were used. Entries were rated on a plot basis. Two replications of the experiment were evaluated in different parts of the field. The first rating was taken approximately 4 days before anthesis and four subsequent ratings were made at 7 - to 10-day intervals. Plots were rated on a 1-to-9 scale, in increments of 0.5 , with 1 being a symptomless plant and 9 being a completely dead plant. Thus, a one-unit difference in rating represented an approximately $12.5 \%$ difference in disease severity.

\section{Southern and Northern blot analyses.}

DNA (using urea-based extraction protocol) and total RNA (using TRI reagent) were isolated as described by Zhang and associates (2005). The gene-specific probe of ZmLOX3 that spans the entire $3^{\prime}$ untranslated region of the gene was amplified by PCR from a cDNA clone representing the ZmLOX3 gene. Equal loading of RNA samples and uniform transfer onto a nylon membrane was confirmed by visualizing RNA stained with ethidium bromide under UV light. Southern and Northern blots were hybridized with the $\mathrm{ZmLOX3}$ genespecific probe in the UltraHyb hybridization buffer and washed according to the manufacturer's protocol (Ambion, Austin, TX, U.S.A.). The blots were exposed to X-ray film (Kodak, Rochester, NY, U.S.A.) in cassettes at $-80^{\circ} \mathrm{C}$ for 4 days (Fig. 1C and D) or for 11 days (Fig. 6A). Blots presented are representative examples of two independent experiments.

\section{Oxylipin profiling.}

The seeds of the lox3-4 mutant and wild type were allowed to imbibe for 1 day and germinated for 4 days at $30^{\circ} \mathrm{C}$ in an incubator in constant darkness. Subsequently, the embryos from 4-day-old germinating seeds were excised and frozen in liquid $\mathrm{N}_{2}$ or used immediately for oxylipin analysis. Oxylipin compounds were analyzed by gas chromatography-mass spectrometry as described by Stumpe and associates (2005).

\section{Distribution of materials.}

Novel materials described in this publication may be available for noncommercial research purposes upon acceptance and signing of a material transfer agreement. In some cases, such materials may contain or be derived from materials obtained from a third party. In such cases, distribution of material will be subject to the requisite permission from any third-party owners, licensors, or controllers of all or part of the material. Plant germplasm will not be made available except at the discretion of the owner and then only in accordance with all applicable governmental regulations. Obtaining any permission will be the sole responsibility of the requestor.

\section{ACKNOWLEDGMENTS}

We thank M. Dickman for critical reading of the manuscript. M. Thon and S. Sukno are acknowledged for providing us with cultures of Colletotrichum graminicola used in this study. This work was supported by the United States Department of Agriculture (USDA)-Agricultural Research Service aflatoxin workshop, the Texas Corn Producers Board, the Texas Agricultural Experiment Station Cropping Systems Program, and National Science Foundation grant IOB-0544428 to M. Kolomiets, and USDA National Research Initiative-Competitive Grants Program 05-35201-16233 to W. B. Shin.

\section{LITERATURE CITED}

Alkan, N., Gadkar, V., Coburn, J., Yarden, O., and Kapulnik, Y. 2004 Quantification of the arbuscular mycorrhizal fungus Glomus intraradices in host tissue using real-time polymerase chain reaction. New Phytol. 161:877-885.

Bate, N. J., and Rothstein, S. J. 1998. C-6-volatiles derived from the lipoxygenase pathway induce a subset of defense-related genes. Plant J. 16:561-569.

Bergstrom, G. C., and Nicholson, R. L. 1999. The biology of corn anthracnose-knowledge to exploit for improved management. Plant Dis. 83:596-608.

Birkett, M. A., Campbell, C. A. M., Chamberlain, K., Guerrieri, E., Hick, A. J., Martin, J. L., Matthes, M., Napier, J. A., Pettersson, J., Pickett, J. A., Poppy, G. M., Pow, E. M., Pye, B. J., Smart, L. E., Wadhams, G. H., Wadhams, L. J., and Woodcock, C. M. 2000. New roles for cis-jasmone as an insect semiochemical and in plant defense. Proc. Natl. Acad. Sci. U.S.A. 97:9329-9334.

Bomblies, K., Wang, R. L., Ambrose, B. A., Schmidt, R. J., Meeley, R. B., and Doebley, J. 2003. Duplicate FLORICAULA/LEAFY homologs zfl1 and zfl2 control inflorescence architecture and flower patterning in maize. Development 130:2385-2395.

Brodhagen, M., and Keller, N. P. 2006. Signalling pathways connecting mycotoxin production and sporulation. Mol. Plant Pathol. 7:285-301.

Brodowsky, I. D., and Oliw, E. H. 1993. Biosynthesis of 8r-hydroperoxylinoleic acid by the fungus Laetisaria arvalis. Biochim. Biophys. Acta 1168:68-72.

Burow, G. B., Nesbitt, T. C., Dunlap, J., and Keller, N. P. 1997. Seed lipoxygenase products modulate Aspergillus mycotoxin biosynthesis. Mol. Plant-Microbe Interact. 10:380-387.

Cacas, J. L., Vailleau, F., Devoine, C., Ennar, N., Agnel, J. P., Tronchet, M., Ponchet, M., Blein, J. P., Roby, D., Triantaphylides, C., and Montillet, J. L. 2005. The combined action of 9 lipoxygenase and galactolipase is sufficient to bring about programmed cell death during tobacco hypersensitive response. Plant Cell Environ. 28:1367-1378.

Calvo, A. M., Hinze, L. L., Gardner, H. W., and Keller, N. P. 1999. Sporogenic effect of polyunsaturated fatty acids on development of Aspergillus spp. Appl. Environ. Microbiol. 65:3668-3673.

Carson, M. L. 1998. Aggressiveness and perennation of isolates of Cochliobolus heterostrophus from North Carolina. Plant Dis. 82:1043-1047. 
Carson, M. L., Stuber, C. W., and Senior, M. L. 2004. Identification and mapping of quantitative trait loci conditioning resistance to southern leaf blight of maize caused by Cochliobolus heterostrophus race $\mathrm{O}$. Phytopathology 94:862-867.

Champe, S. P., and Elzayat, A. A. E. 1989. Isolation of a sexual sporulation hormone from Aspergillus nidulans. J. Bacteriol. 171:3982-3988.

Champe, S. P., Rao, P., and Chang, A. 1987. An endogenous inducer of sexual development in Aspergillus nidulans. J. Gen. Microbiol. 133:1383-1387.

Das, L., and Martinssen, R. 1995. Site-selected transposon mutagenesis at the hcf106 locus in maize. Plant Cell 7:287-294.

Diener, U. L., Cole, R. J., Sanders, T. H., Payne, G. A., Lee, L. S., and Klich, M. A. 1987. Epidemiology of aflatoxin formation by Aspergillus flavus. Annu. Rev. Phytopathol. 25:249-270.

Dong, X. 1998. SA, JA, ethylene, and disease resistance in plants. Curr. Opin. Plant Biol. 1:316-323.

Fammartino, A., Cardinale, F., Göbel, C., Mène-Saffrané, L., Fournier, J., Feussner, I., and Esquerré-Tugayé. M T. 2007. Characterization of a divinyl ether biosynthetic pathway specifically associated with pathogenesis in tobacco. Plant Physiol 143:378-388.

Feussner, I., and Wasternack, C. 2002. The lipoxygenase pathway. Annu. Rev. Plant Biol. 53:275-297.

Göbel, C., Feussner, I., Schmidt, A., Scheel, D., Sanchez-Serrano, J., Hamberg, M., and Rosahl, S. 2001. Oxylipin profiling reveals the preferential stimulation of the 9-lipoxygenase pathway in elicitor-treated potato cells. J. Biol. Chem. 276:6267-6273.

Göbel, C., Feussner, I., Hamberg, M., and Rosahl, S. 2002. Oxylipin profiling in pathogen-infected potato leaves. Biochim. Biophys. Acta Mol. Cell Biol. Lipids 1584:55-64.

Göbel, C., Feussner, I., and Rosahl, S. 2003. Lipid peroxidation during the hypersensitive response in potato in the absence of 9-lipoxygenases. J. Biol. Chem. 278:52834-52840.

Hamberg, M., Zhang, L. Y., Brodowsky, I. D., and Oliw, E. H. 1994. Sequential oxygenation of linoleic acid in the fungus Gaeumannomyces graminis - stereochemistry of dioxygenase and hydroperoxide isomerase reactions. Arch. Biochem. Biophys. 309:77-80.

Hamberg, M., Sanz, A., Rodriguez, M. J., Calvo, A. P., and Castresana, C. 2003. Activation of the fatty acid alpha-dioxygenase pathway during bacterial infection of tobacco leaves-formation of oxylipins protecting against cell death. J. Biol. Chem. 278:51796-51805.

Herman, R. 1998. Oxylipin production and action in fungi and related organisms. Pages 115-130 in: Eicosanoids and Related compounds in Plants and Animals. A. F. Rowley, H. Kuhn, and T. Schewe, eds. Princeton University Press, Princeton, NJ, U.S.A.

Howe, G. A., and Schilmiller, A. L. 2002. Oxylipin metabolism in response to stress. Curr. Opin. Plant Biol. 5:230-236.

Kock, J. L. F., Strauss, C. J., Pohl, C. H., and Nigam, S. 2003. The distribution of 3-hydroxy oxylipins in fungi. Prostag. Oth. Lipid M. 71:85-96.

Kolomiets, M. V., Chen, H., Gladon, R. J., Braun, E. J., and Hannapel, D. J. 2000. A leaf lipoxygenase of potato induced specifically by pathogen infection. Plant Physiol. 124:1121-1130.

La Camera, S., Geoffroy, P., Samaha, H., Ndiaye, A., Rahim, G., Legrand, M., and Heitz, T. 2005. A pathogen-inducible patatin-like lipid acyl hydrolase facilitates fungal and bacterial host colonization in Arabidopsis. Plant J. 44:810-825.

Mazur, P., Nakanishi, K., Elzayat, A. A. E., and Champe, S. P. 1991. Structure and synthesis of sporogenic psi factors from Aspergillus nidulans. J. Chem. Soc. Chem. Commun. 20:1486-1487.

McDonald, T., Devi, T., Shimizu, K., Sim, S., and Keller, N. P. 2004. Signaling events connecting mycotoxin biosynthesis of sporogenic psi factors from Aspergillus and Fusarium spp. Pages 139-147 in: New Horizon of Mycotoxicology for Assuring Food Safety. T. Yoshizawa, ed. Bikohsha Co., Takamatsu, Japan.

Meeley, R. B., and Briggs, S. 1995. Reverse genetics for maize. Maize Genet. Coop. Newsl. 69:67-82.

Noverr, M. C., Erb-Downward, J. R., and Huffnagle, G. B. 2003. Production of eicosanoids and other oxylipins by pathogenic eukaryotic microbes. Clin. Microbiol. Rev. 16:517-533.

Rance, I., Fournier, J., and Esquerre-Tugaye, M. T. 1998. The incompatible interaction between Phytophthora parasitica var. nicotianae race 0 and tobacco is suppressed in transgenic plants expressing antisense lipoxygenase sequences. Proc. Natl. Acad. Sci. U.S.A. 95:6554-6559.

Sagaram, U. S., Kolomiets, M., and Shim, W. B. 2006. Regulation of fumonisin biosynthesis in Fusarium verticillioides-Maize system. Plant Pathol. J. 22:203-210.

Shim, W. B., and Woloshuk, C. P. 2001. Regulation of fumonisin B-1 biosynthesis and conidiation in Fusarium verticillioides by a cyclin-like (C-type) gene, FCC1. Appl. Environ. Microbiol. 67:1607-1612.

Stumpe, M., Carsjens, J. G., Stenzel, I., Gobel, C., Lang, I., Pawlowski, K., Hause, B., and Feussner, I. 2005. Lipid metabolism in arbuscular mycorrhizal roots of Medicago truncatula. Phytochemistry 66:781-791.

Su, C., Sahlin, M., and Oliw, E. H. 1998. A protein radical and ferryl intermediates are generated by linoleate diol synthase, a ferric hemeprotein with dioxygenase and hydroperoxide isomerase activities. J. Biol. Chem. 273:20744-20751.

Thon, M. R., Nuckles, E. M., Takach, J. E., and Vaillancourt, L. J. 2002. CPR1: A gene encoding a putative signal peptidase that functions in pathogenicity of Colletotrichum graminicola to maize. Mol. PlantMicrobe Interact. 15:120-128.

Torregrosa, C., Cluzet, S., Fournier, J., Huguet, T., Gamas, P., Prosperi, J M., Esquerre-Tugaye, M. T., Dumas, B., and Jacquet, C. 2004. Cytological, genetic, and molecular analysis to characterize compatible and incompatible interactions between Medicago truncatula and Colletotrichum trifolii. Mol. Plant-Microbe Interact. 17:909-920.

Tsitsigiannis, D., Kowieski, T. M., Zarnowski, R., and Keller, N. P. 2004a Endogenous lipogenic regulators of spore balance in Aspergillus nidulans. Eukaryot. Cell 3:1398-1411.

Tsitsigiannis, D. I., Zarnowski, R., and Keller, N. P. 2004b. The lipid body protein, PpoA, coordinates sexual and asexual sporulation in Aspergillus nidulans. J. Biol. Chem. 279:11344-11353.

Tsitsigiannis, D. I., and Keller, N. P. 2006. Oxylipins act as determinants of natural product biosynthesis and seed colonization in Aspergillus nidulans. Mol. Microbiol. 59:882-892.

Tsitsigiannis, D. I., and Keller, N. P. 2007. Oxylipins as developmental and host-fungal communication signals. Trends Microbiol. doi:10.1016/j.tim.2007.01.005. Published online.

Turner, J. G., Ellis, C., and Devoto, A. 2002. The jasmonate signal pathway. Plant Cell 14:S153-S164.

Voigt, C. A., Schafer, W., and Salomon, S. 2005. A secreted lipase of Fusarium graminearum is a virulence factor required for infection of cereals. Plant J. 42:364-375.

Weber, H., Chételat, A., Caldelari, D., and Farmer, E. E. 1999. Divinyl ether fatty acid synthesis in late blight-diseased potato leaves. Plant Cell 11:485-494.

Wilson, R. A., Gardner, H. W., and Keller, N. P. 2001. Cultivar-dependent expression of a maize lipoxygenase responsive to seed infesting fungi. Mol. Plant-Microbe Interact. 14:980-987.

Zhang, J. L., Simmons, C., Yalpani, N., Crane, V., Wilkinson, H., and Kolomiets, M. 2005. Genomic analysis of the 12-oxo-phytodienoic acid reductase gene family of Zea mays. Plant Mol. Biol. 59:323-343. 